\title{
Atividade fitorreguladora de jasmonatos produzidos por Botryosphaeria rhodina
}

\author{
Any MP Linares; Camila Hernandes; Suzelei de C França; Miriam Verginia Lourenço \\ Universidade de Ribeirão Preto-Unid. Biotecnologia, Av. Costábile Romano, 2001, Ribeirânia, 14096-900 Ribeirão Preto-SP; \\ mvlouren@unaerp.br
}

\section{RESUMO}

O ácido jasmônico e seus derivados jasmonatos são reguladores vegetais endógenos produzidos por várias espécies vegetais, que atuam no mecanismo de defesa das plantas e agem como sinalizadores de estresse. O objetivo deste trabalho foi comparar o potencial fitorregulador de um fermentado, obtido pela fermentação do fungo filamentoso Botryosphaeria rhodina, contendo jasmonatos, comparado à ação do ácido jasmônico (AJ) usado como padrão. Sementes selecionadas de Capsicum frutescens (pimenta malagueta) e Physalis angulata (camapú) foram plantadas em terra contendo fertilizantes orgânicos e minerais. Plantas após 37 dias de germinação foram tratadas via pulverização foliar com duas diferentes concentrações de $\mathrm{AJ}$ (25,0 e 50,0 $\left.\mathrm{mg} \mathrm{L}^{-1}\right)$ e com fermentado contendo jasmonatos (correspondendo a $50 \mathrm{mg} \mathrm{L}^{-1}$ de AJ) e como controle foi utilizado água. Os experimentos foram realizados em casa de vegetação, em blocos casualizados, com três repetições de cinco plantas por tratamentos, com os tratamentos dispostos em fatorial de 4x1 (1 controle; 2 doses de AJ e 1 dose do filtrado). A avaliação das plantas foi realizada 80 dias após a aplicação de $\mathrm{AJ}$ e o fermentado. Plantas controle de Capsicum produziram 6,4 frutos/planta enquanto que plantas tratadas com 25,0 e 50,0 $\mathrm{mg} \mathrm{L}^{-1}$ de AJ produziram 7,2 frutos/planta e 9,2 frutos/planta, respectivamente e plantas tratadas com o fermentado produziram 11,7 frutos/planta. Adicionalmente, plantas controle de Physalis produziram 10,5 botões/planta e quando tratadas com 25,0 e 50,0 $\mathrm{mg} \mathrm{L}^{-1}$ de AJ produziram 15,5 e 16,0 botões/planta, respectivamente. Plantas tratadas com o fermentado dobraram a produção de botões/planta $(23,0)$ quando comparados ao controle. Resultados obtidos validam o potencial fitorregulador do AJ e do fermentado contendo jasmonatos, comprovado pelo aumento na produção de frutos e botões florais pelas espécies vegetais testadas, evidenciando assim o potencial de uso deste fermentado como alternativa de menor custo ao AJ obtido comercialmente.

Palavras-chave: Capsicum frutescens, Physalis angulata, fitorregulador, ácido jasmônico, produção vegetal.

\begin{abstract}
Phytoregulatory activity of jasmonates produced by Botryosphaeria rhodina
\end{abstract}

Jasmonic acid (JA) and its jasmonate derivatives are endogenous hormones produced by numerous plant species that interfere on plant defense mechanism and act as stress signaling. The aim of this work was to compare the plant growth regulator potential of a fermented broth, obtained by the fermentation of the filamentous fungus Botryosphaeria rhodina, containing jasmonates to the action of the jasmonic acid used as standard. Selected seeds of Capsicum frutescens (pimenta malagueta) and Physalis angulata (camapú) were planted in soil containing mineral and organic fertilizer. Thirty seven days after germination seedlings were sprinkled with two different concentrations of JA (25.0 and $\left.50.0 \mathrm{mg} \mathrm{L}^{-1}\right)$ and with the jasmonate-containing fermented broth (corresponding to $50 \mathrm{mg} \mathrm{L}^{-1}$ of JA). Water was used as control. The experiment was carried out in a greenhouse in a completely randomized block design, with three replications with five plants and treatments applied to a $4 \times 1$ factorial ( 1 control; 2 doses of JA and 1 dose of filtrated). The evaluation of seedlings was performed 80 days after scattering with JA and the fermented broth. Capsicum control plants produced 6.4 fruits/plant, while plants sprinkled with 25.0 and $50.0 \mathrm{mg} \mathrm{L}^{-1} \mathrm{JA}$ produced 7.2 and 9. 2 fruits/plant respectively and plants sparged with the fermented broth produced 11.7 fruits/plant. Moreover, Physalis control plants produced 10.5 buds/plant and when sprinkled with 25.0 and 50.0 mg L ${ }^{-1}$ JA produced 15.5 and 16.0 buds/plant respectively. Plantlets sparged with the fermented broth doubled the production of buds/plant (23.0) when compared to the control. The results obtained validate the growth regulator potential of JA and of the fermented broth on the tested plants, evidenced by the increased production of fruits and flower buds by the plant species tested. Thus, the fermented broth of the fungus Botryosphaeria rhodina is a lower cost alternative to commercially obtained JA.

Keywords: Capsicum frutescens, Physalis angulata, plant growth regulator, jasmonic acid, plant production.

(Recebido para publicação em 29 de julho de 2009; aceito em 22 de setembro de 2010) (Received on July 29, 2009; accepted on September 22, 2010)

$\mathrm{O}$ s jasmonatos constituem um grupo de substâncias reguladoras endógenas do crescimento vegetal, identificadas em uma grande variedade de espécies vegetais tais como Jasminun grandiflorum, Rosmarinus officinalis Arthemisia absinthium L., sementes imaturas de Phaseolus vulgaris L. e Dolicos lablab L. (Meyer et al., 1984).
Representa um novo tipo de hormônio vegetal, que desempenha papel crucial no crescimento, desenvolvimento e resposta a diferentes condições de estresse ambiental da planta (Cortês, 2000).

$\mathrm{O}$ ácido jasmônico $(\mathrm{AJ})$ e seus derivados (jasmonatos) estão relacionados a mecanismos de defesa vegetal. Eles induzem a expressão de genes que codificam proteínas específicas, como inibidores de proteases, enzimas envolvidas com a produção de flavonóides e diferentes proteínas relacionadas com doenças (Cortês, 2000), desempenhando ainda papel importante na defesa das plantas contra danos causados por raios UV-B (Schaller, 2001).

Morfológica e fisiologicamente, 
os jasmonatos apresentam tanto efeito promotor como inibidor nos vegetais, sendo alguns destes efeitos semelhantes àqueles causados pelo ácido abscísico e pelo etileno. Existem estudos mostrando a ação dos jasmonatos sobre a senescência, acúmulo de proteínas de armazenamento, desenvolvimento de embriões e biossíntese de metabólitos secundários (Carletti et al., 1999).

Em testes realizados com aplicação exógena de AJ na agricultura obtiveramse vários resultados positivos, como o aumento do rendimento de culturas de morango, soja e cana-de-açúcar; estimulação da formação de tubérculos em inhame e batata (Koda, 1992) e amadurecimento em frutos de tomate e maçã (Sembdner \& Parthier, 1993). Além da produção de inibidores de proteases em tomateiros (Farmer \& Ryan, 1990) e em arroz, houve inibição da germinação de esporos de Pyricularia oryzae, fungo que provoca doença conhecida como tição do arroz ou brusone (Hamberg \& Garder, 1992).

A produção de jasmonatos pode ser realizada através de processo de extração de plantas superiores, por via química ou ainda por fermentação microbiana. Atualmente, a via predominante de obtenção é a extração direta de fontes vegetais, com baixa eficiência de produção, sendo necessários, por exemplo, $800 \mathrm{~kg}$ de flores de J. grandiflorum para produzir $1 \mathrm{~kg}$ de jasmona contendo apenas 0,25\% de AJ (Dhandhukia \& Takkar, 2008), concorrendo assim para um elevado custo destes produtos no mercado mundial (Altuna et al., 2000).

A produção de jasmonatos a partir de micro-organismos ainda é limitada, porém alguns relatos demonstram ser esta via economicamente vantajosa (Miersch, 1987), visto que linhagens do fungo Botryosphaeria rhodina são capazes de acumular, dentre os jasmonatos produzidos, quantidades superiores a $500 \mathrm{mg} \mathrm{L}^{-1}$ de (-)-7-iso-AJ, durante a fermentação (Miersch et al., 1989).

Para o estudo foram escolhidas duas espécies vegetais, Capsicum frutescens e Physalis angulata, ambas da família Solanaceae.

A espécie $P$. angulata tem sido estudada atualmente em virtude de seu potencial em produzir fisalinas, uma classe de compostos que apresenta amplo espectro de atividade biológica, tais como anti-inflamatório, antiviral, antimicrobiano e antitumoral, dentre outras (Ribeiro et al., 2002).

A pimenta $C$. frutescens é uma solanácea de alto valor comercial dentre as especiarias, sendo um gênero de grande importância sócio-econômica (Fonseca, 2006).

Diante do exposto esse estudo objetivou avaliar a atividade fitorreguladora do ácido jasmônico e do filtrado do fungo Botryosphaeria rhodina, contendo jasmonatos, sobre culturas de $P$. angulata e C. frutescens (Solanáceas).

\section{MATERIAL E MÉTODOS}

Buscando verificar a atividade fitorreguladora do ácido jasmônico (AJ) e do filtrado do fungo $B$. rhodina sobre plantas de $P$. angulata e $C$. frutescens foram realizados quatro tratamentos para cada uma das espécies vegetais, que consistiram de: (1) controle, (2) filtrado de $B$. rhodina (contendo $50 \mathrm{mg}$ de AJ $\mathrm{L}^{-1}$ ), (3) solução de AJ a $25 \mathrm{~mL} \mathrm{~L}^{-1} \mathrm{e}$, (4) solução de AJ a $50 \mathrm{mg} \mathrm{L}^{-1}$.

O filtrado foi obtido pela fermentação da linhagem kifn 3.1 do fungo $B$. rhodina em meio de cultura $\mathrm{M}_{2}$ (Eng et al., 1998) composto por $50 \mathrm{~g} \mathrm{~L}^{-1} \mathrm{de}$ sacarose, 7,5 $\mathrm{g} \mathrm{L}^{-1}$ de $\mathrm{KNO}_{3}, 2 \mathrm{~g} \mathrm{~L}^{-1} \mathrm{de}$ $\mathrm{KH}_{2} \mathrm{PO}_{4}, 0,6 \mathrm{~g} \mathrm{~L}^{-1}$ de $\mathrm{MgSO}_{4} 7 \mathrm{H}_{2} \mathrm{O}, 0,3$ $\mathrm{g} \mathrm{L}^{-1}$ de $\mathrm{KCl}, 0,6 \mathrm{~g} \mathrm{~L}^{-1}$ de $\mathrm{FeSO}_{4} 7 \mathrm{H}_{2} \mathrm{O}$, $0,030 \mathrm{~g} \mathrm{~L}^{-1}$ de $\mathrm{ZnSO}_{4} 7 \mathrm{H}_{2} \mathrm{O}, 0,030 \mathrm{~g}$ $\mathrm{L}^{-1} \mathrm{de} \mathrm{MnSO}_{4}, 0,030 \mathrm{~g} \mathrm{~L} \mathrm{~L}^{-1} \mathrm{de}$ $\mathrm{Na}_{2} \mathrm{MoO}_{4} 2 \mathrm{H}_{2} \mathrm{O}, 0,030 \mathrm{~g} \mathrm{~L}^{-1} \mathrm{de}$ $\mathrm{CuSO}_{4} 7 \mathrm{H}_{2} \mathrm{O}$ e $1 \mathrm{~g} \mathrm{~L}^{-1}$ de extrato de levedura; com $\mathrm{pH}$ fixado em 5,5. Para as fermentações, o correspondente a1/8 da placa micelial foi inoculado em frascos tipo Erlenmeyer de $250 \mathrm{~mL}$ de capacidade contendo $50 \mathrm{~mL}$ de meio de cultura. A fermentação foi mantida durante 13 dias sob condições estáticas, na ausência de luz e a $30^{\circ} \mathrm{C}$.

Após a fermentação, o líquido foi filtrado a vácuo, o pH ajustado para 3,0 com $\mathrm{HCl}$ 4M. Em seguida, o filtrado foi submetido à extração com acetato de etila na proporção $1: 1$, por três vezes. As frações orgânicas foram reunidas, dessecadas com $\mathrm{Na}_{2} \mathrm{SO}_{4}$, e em seguida as amostras foram evaporadas num evaporador rotativo a vácuo.
A quantificação de AJ nos extratos foi realizada utilizando-se um cromatógrafo Shimadzu (LC-10AD vp) acoplado a um detector de arranjo de diodo. Utilizou-se uma coluna Supelcosil C18 (25 cm x 4,6 mm id, 5 micras) e um sistema solvente composto de $\mathrm{MeOH}$ : ácido acético $0,1 \%(60: 40)$. O fluxo de solvente foi de $0,85 \mathrm{~mL} \mathrm{~min}{ }^{-1}$ sendo a análise monitorada a $210 \mathrm{~nm}$. Para a quantificação fez-se uso do método do padrão externo, através do traçado de uma curva de calibração utilizando-se uma solução padrão autêntica de AJ (Sigma) em concentrações variando entre 0,1-1,0 $\mathrm{mg} \mathrm{mL}^{-1}$.

As sementes de $P$. angulata e $C$. frutescens foram plantadas diretamente nos vasos de $2 \mathrm{~L}$ de capacidade, contendo uma mistura de solo e adubos orgânico e mineral (1:1); plantou-se 4 sementes em cada recipiente com posterior desbaste de plântulas.

Cada tratamento constituiu de parcelas contendo 3 replicatas de 5 vasos com 2 plantas em cada um deles. Visando padronizar o tamanho das plantas, 15 dias após o plantio foi realizado um desbaste uniformizando assim o material vegetal.

A aplicação, via pulverização foliar, das soluções aconteceu no $37^{\circ}$ dia após o plantio das sementes e as concentrações usadas foram 25 e $50 \mathrm{mg} \mathrm{L}^{-1} \mathrm{AJ}$ e $50 \mathrm{mg}$ $\mathrm{L}^{-1}$ AJ no filtrado. Os vasos foram mantidos em casa de vegetação, recobertos com sombreamento plástico ventilado e irrigados duas vezes ao dia, de manhã e à tarde, permanecendo nessas condições até a coleta dos dados.

As plantas foram colhidas e as medidas de altura, número de frutos e botões florais de cada uma, realizada individualmente. Os materiais coletados foram acondicionados separadamente em sacos de papel Kraft. Este material foi seco em estufa a $50^{\circ} \mathrm{C}$ por 5 dias, depois pesado e, assim, definidos os respectivos pesos secos. As médias foram comparadas pelo teste t a $1 \%$ de probabilidade.

\section{RESULTADOS E DISCUSSÃO}

Os tratamentos realizados resultaram em aumentos significativos de produção, porém com diferenças entre 
as plantas testadas.

Quando se analisou a resposta de C. frutescens aos tratamentos (Tabela 1) verificou-se que a altura das plantas no tratamento controle foi de $13,0 \mathrm{~cm}$ e na dose de $25 \mathrm{mg} \mathrm{L}^{-1}$ de AJ foi de 13,6 $\mathrm{cm}$, não apresentando diferenças estatísticas significativas entre si. As plantas tratadas com AJ na dose de $50 \mathrm{mg} \mathrm{L}^{-1}$ apresentaram altura superior atingindo valores de $15,9 \mathrm{~cm}$ e com o fermentado o resultado foi semelhante, $15,2 \mathrm{~cm}$, sendo que estes não apresentaram diferenças significativas entre si em nível de $1 \%$ pelo teste $t$. Infere-se a este resultado uma resposta de crescimento de plantas de $C$. frutescens baseada no aspecto quantitativo da presença do regulador vegetal. Os parâmetros biométricos deste experimento atestam uma boa precisão do mesmo.

Entretanto, quando foi analisada a produção de frutos pelas plantas, verificou-se que houve resposta linear no aumento desse número, à medida que foram adicionados maiores teores do regulador vegetal nas plantas. $\mathrm{O}$ maior número de frutos por planta foi obtido com a aplicação do fermentado $(11,7$ frutos/planta), diferindo dos demais tratamentos, onde o controle apresentou o menor número de frutos $(6,4$ frutos/ planta), seguido da dose $25 \mathrm{mg} \mathrm{L}^{-1} \mathrm{AJ}$
(7,2 frutos/planta) e $50 \mathrm{mg} \mathrm{L}^{-1} \mathrm{AJ}(9,2$ frutos/planta). Uma melhor resposta do fermentado pode ter sido devido à presença de outros jasmonatos no mesmo. A precisão deste experimento também foi suficientemente alta para discriminar as diferenças entre os tratamentos.

Deve ser esperado que os jasmonatos desempenhem função de formação de flores, frutos e sementes por causa de seus níveis relativamente altos no desenvolvimento dos tecidos reprodutivos das plantas. A presença de jasmonatos nas plantas e de derivados de ácidos graxos voláteis relacionados pode estar envolvida na atração de insetos responsáveis pela dispersão de pólen. Outro aspecto do desenvolvimento de flores, frutos e sementes que pode ser modulado pelos jasmonatos inclui o amadurecimento dos frutos, a composição de carotenóides nos mesmos e a expressão de genes que codificam a produção de sementes e proteínas vegetativas de estoque.

Com relação ao número de botões florais, após os tratamentos, houve resposta significativa nos tratamentos $50 \mathrm{mg} \mathrm{L}^{-1} \mathrm{AJ}$ (7,9 botões/planta) e fermentado ( 8,2 botões/planta) em relação ao controle ( 5,6 botões/planta) e em 25 $\mathrm{mg} \mathrm{L}^{-1} \mathrm{AJ}$ (6,0 botões florais/planta). Neste caso, estatisticamente, os tratamentos $50 \mathrm{mg} \mathrm{L}^{-1} \mathrm{AJ}$ e fermentado não diferiram entre si. Embora o coeficiente de variação deste caráter tenha sido superior aos demais, o mesmo ocorreu pela menor média do ensaio e não pela precisão, o que é facilmente verificado pela diferença mínima significativa do mesmo.

As características número de botões florais, número de frutos e peso seco de botões florais e frutos estão altamente relacionados entre si, como respostas ao regulador vegetal seguindo a mesma tendência nos três tratamentos.

A maior resposta na produção de peso seco de frutos e botões florais foi obtida com a aplicação do fermentado (15,9 g), diferindo significativamente a $1 \%$ de significância pelo teste $\mathrm{t}$ do tratamento controle $(11,4 \mathrm{~g})$ e $25 \mathrm{mg} \mathrm{L}^{-1}$ AJ (13,0 g). O tratamento $50 \mathrm{mg} \mathrm{L}^{-1} \mathrm{AJ}$ $(13,6 \mathrm{~g})$ não diferiu significativamente do fermentado e de $25 \mathrm{mg} \mathrm{L}^{-1} \mathrm{AJ}$, indicando neste caráter uma resposta quase linear de dosagem do regulador vegetal. Outra observação importante, embora não tenha sido mensurada, foi quanto ao tamanho dos frutos nos tratamentos na presença do regulador vegetal, onde os mesmo apresentaram tamanho maior que os frutos das plantas controle.

Analisando-se os resultados obtidos para $P$. angulata quanto ao caráter altura de plantas, estes indicaram a ausência de

Tabela 1. Altura de plantas, número de frutos e de botões florais, peso seco de planta, frutos e botões florais de Capsicum frutescens e de Physalis angulata após tratamentos com $25 \mathrm{mg} \mathrm{L}^{-1}$ de ácido jasmônico (AJ), $50 \mathrm{mg} \mathrm{L}^{-1} \mathrm{AJ}$ e filtrado de Botryosphaeria rhodina (plant height, number of fruit and flower buds, dry weight of plant, fruits and floral buds from Capsicum frutescens and from Physalis angulata after treatments with $25 \mathrm{mg} \mathrm{L}^{-1}$ of jasmonic acid (AJ), $50 \mathrm{mg} \mathrm{L}^{-1} \mathrm{JA}$ and filtrated of Botryosphaeria rhodina). Ribeirão Preto, UNAERP, 2008.

\begin{tabular}{|c|c|c|c|c|c|}
\hline Tratamento & Altura (cm) & $\begin{array}{l}\text { Número de } \\
\text { frutos }\end{array}$ & $\begin{array}{c}\text { Número de } \\
\text { botões florais }\end{array}$ & $\begin{array}{l}\text { Peso seco da } \\
\text { planta (g) }\end{array}$ & $\begin{array}{l}\text { Peso seco de } \\
\text { frutos + bototes } \\
\text { florais (g) }\end{array}$ \\
\hline & \multicolumn{5}{|c|}{ Capsicum frutescens } \\
\hline Controle & $13,0 b^{1}$ & $6,4 \mathrm{c}$ & $5,6 \mathrm{~b}$ & $15,0 \mathrm{a}$ & $11,4 \mathrm{~b}$ \\
\hline AJ $25 \mathrm{mg} \mathrm{L}^{-1}$ & $13,6 \mathrm{~b}$ & $7,2 \mathrm{bc}$ & $6,0 \mathrm{~b}$ & $15,5 \mathrm{a}$ & $13,0 \mathrm{~b}$ \\
\hline AJ $50 \mathrm{mg} \mathrm{L}^{-1}$ & $15,9 \mathrm{a}$ & $9,2 \mathrm{~b}$ & 7,9 a & $15,2 \mathrm{a}$ & $13,6 \mathrm{ab}$ \\
\hline Fermentado (AJ $50 \mathrm{mg} \mathrm{L}^{-1}$ ) & $15,2 \mathrm{a}$ & $11,7 \mathrm{a}$ & $8,2 \mathrm{a}$ & $16,1 \mathrm{a}$ & $15,9 \mathrm{a}$ \\
\hline \multirow[t]{2}{*}{$\mathrm{CV}(\%)$} & 6,7 & 14,5 & 16,2 & 13,3 & 11,5 \\
\hline & \multicolumn{5}{|c|}{ Physalis angulata } \\
\hline Controle & $21,0 \mathrm{a}$ & $19,5 \mathrm{a}$ & $10,5 \mathrm{c}$ & $23,9 \mathrm{a}$ & $70,3 \mathrm{c}$ \\
\hline AJ $25 \mathrm{mgL}^{-1}$ & $22,0 \mathrm{a}$ & $25,0 \mathrm{a}$ & $15,5 \mathrm{~b}$ & $25,9 \mathrm{a}$ & $85,0 \mathrm{~b}$ \\
\hline AJ $50 \mathrm{mgL}^{-1}$ & $20,5 \mathrm{a}$ & $19,0 \mathrm{a}$ & $16,0 \mathrm{~b}$ & $26,9 \mathrm{a}$ & $78,2 \mathrm{c}$ \\
\hline Fermentaddo (AJ $50 \mathrm{mg} \mathrm{L}^{-1}$ ) & $22,0 \mathrm{a}$ & $23,5 \mathrm{a}$ & $23,0 \mathrm{a}$ & $27,3 \mathrm{a}$ & $92,4 \mathrm{a}$ \\
\hline CV (\%) & 7,8 & 21,7 & 7,9 & 6,4 & 9,1 \\
\hline
\end{tabular}

${ }^{1}$ Médias seguidas de mesma letra não diferem estatisticamente pelo teste t a $1 \%$ de probabilidade. (means followed by the same letter do not differ by the $\mathrm{T}$ test at $1 \%$ ). 
diferenças significativas. Isto demonstra que não foi identificada nenhuma influência do AJ nas duas doses aplicadas, assim como no fermentado, em comparação ao controle (Tabela 1). O coeficiente de variação do experimento foi baixo 7,8\%, indicando variação relativamente baixa entre as alturas, dentro e entre os tratamentos.

Segundo Leon \& Sanches-Serrano (1999) fatores como concentração de jasmonatos, estado fisiológico da planta, assim como, as condições ambientais em que as mesmas se encontram influenciam nas respostas aos estímulos por jasmonatos.

Os resultados obtidos no presente trabalho corroboraram com os obtidos por Castro et al. (1999) onde a aplicação exógena de $\mathrm{AJ}$ às gemas de tubérculos, quando cultivadas in vitro, provocou uma importante expansão das células de crescimento radial e nem tanto longitudinal, de forma semelhante às plantas de $P$. angulata que não cresceram tanto em altura, mas houve desenvolvimento maior da parte reprodutiva.

Quanto ao número de frutos analisados nos quatro tratamentos de $P$. angu$l a t a$, verificou-se não haver diferenças significativas. A causa mais provável desta não significância pode ser devida à alta variância medida, para o caráter, nos diferentes vasos dentro de cada tratamento. Considerando-se que os vasos foram semeados com excesso de indivíduos, seguido de desbaste seletivo de plântulas para minimizar as diferenças de porte entre elas, e as condições experimentais controladas permitindo a máxima uniformidade ambiental, não seriam esperadas, a priori, as variações encontradas. Entretanto, trata-se de uma espécie não domesticada, encontrada na natureza como erva invasora, o que explica a falta de uniformidade genética entre indivíduos, mesmo após o uso do artifício do desbaste seletivo, dificultando o isolamento dos fatores do contraste. Possivelmente uma maior amostragem de indivíduos para a representação da média do caráter teria menor flutuação de magnitude do mesmo.

Os resultados obtidos nas avaliações da média dos números de botões florais permitiram verificar uma melhor resposta nas plantas tratadas quando comparadas ao controle (10,5 botões/ planta). Plantas tratadas com a menor dose de AJ apresentaram resultados estatisticamente semelhantes àquelas tratadas com a maior dose de AJ (15,5 e 16 botões florais/planta, respectivamente), enquanto as plantas tratadas com o fermentado contendo jasmonatos geraram maior número de botões florais/ planta $(23,0)$.

Foi possível verificar ainda que, embora as plantas tivessem se mantido com alturas semelhantes, o número de frutos encontrados no momento da colheita, nos tratamentos onde foi aplicado o AJ e, principalmente, o filtrado contendo jasmonatos, houve resposta clara na continuidade de formação de botões florais, indicando um maior potencial de produção de frutos pelas plantas nestas condições.

Os coeficientes de variação relativos aos diferentes tratamentos e ao experimento todo para o caráter número de botões florais foram baixos, atestando a repetibilidade deste caráter, apesar das considerações anteriores de variabilidade genética intrínseca da espécie.

Os vários efeitos dos jasmonatos como regulador vegetal estão relacionados, dentre outros fatores, à estrutura do composto e à sua concentração. Assim em algumas plantas altas concentrações de AJ $(\sim 100 \mu \mathrm{M})$ exogenamente aplicadas promoveram a senescência (Parthier, 1991) e esse efeito parece ser devido à aplicação dessas concentrações altas e não fisiológicas de AJ. Entretanto, endogenamente os maiores níveis de jasmonatos estão presentes em tecidos jovens e em crescimento, evidenciando seu papel como estimulador do desenvolvimento vegetal (Creelman \& Mullet, 1997).

Os diferentes materiais colhidos durante os experimentos foram devidamente secos em estufa, gerando valores de massas secas destes materiais. Assim, quanto ao peso seco apenas os tratamento $25 \mathrm{mg} \mathrm{L}^{-1} \mathrm{AJ}(85,0 \mathrm{~g})$ e fermentado $(92,4 \mathrm{~g})$ foram diferentes e superiores aos demais tratamentos $(70,3 \mathrm{~g}$ para o controle e 78,2 g para $50 \mathrm{mg} \mathrm{L}^{-1} \mathrm{AJ}$ ). Verificou-se que a diferença mínima significativa correspondeu a apenas $14 \%$ da média geral do ensaio para o caractere peso seco de frutos e botões florais, atestando a boa precisão do experimento. $\mathrm{O}$ coeficiente de variação deste caractere também é igualmente indicativo desta qualidade experimental. Essas diferenças em peso seco são devidas aos tamanhos dos frutos gerados serem superiores nos tratamentos quando comparados aos controles.

Quanto aos pesos secos das plantas (caules e folhas) estes não apresentaram diferenças significativas e as variações de peso dentro e entre as parcelas foram pouco expressivas, o que se refletiu na baixa variância e no coeficiente de variação. Estes dados claramente demonstram que, em $P$. angulata, a aplicação do AJ puro ou do fermentado contendo jasmonatos não afetou o desenvolvimento vegetativo das plantas.

A ação do AJ exógeno sobre as espécies vegetais é diferenciada, e embora a literatura mostre que em altas concentrações $(\geq 100 \mu \mathrm{M})$ possa promover senescência em algumas espécies vegetais, nossos resultados evidenciaram que a maior concentração de AJ utilizada (200 $\mu \mathrm{M}$ ), quer puro ou no fermentado, foi mais efetiva sobre a produção dos frutos e botões florais nas plantas testadas, e nenhum sinal de toxidez foi verificado nas mesmas. Havendo ainda um prolongamento no período de frutificação em C. frutescens.

Outros efeitos dos jasmonatos sobre culturas vegetais têm sido demonstrados. Dados de Carli (1999), em experimentos com sementes de soja evidenciaram que o AJ, embora não tenha promovido efeito significativo no aumento de matéria fresca, induziu a síntese de novo de lipoxigenases nas sementes. Tebayashi et al. (2007), em experimentos com cotilédones de Capsicum anuum tratados com AJ registraram um aumento na produção de cafeoilputrescina, um composto inibidor da ovoposição de Liriomyza trifolii (Díptera), causadora de sérios danos a diversas espécies vegetais.

Essas informações mostram as diferentes ações dos jasmonatos sobre as espécies vegetais, de forma que sobre $C$. frutescens e $P$. angulata tanto AJ como o filtrado promoveram incremento de biomassa seca, principalmente na produção de frutos e botões florais, confirmando seu potencial efeito fitorregulador. 
A utilização do fermentado como fitorregulador é uma alternativa viável na aplicação de jasmonatos visando o incremento das culturas a um custo inferior, visto a produção de AJ pelo fungo Botryosphaeria rhodina apresentar-se mais promissora que a extração de fontes naturais.

\section{AGRADECIMENTOS}

À Fundação de Amparo à Pesquisa do Estado de São Paulo (FAPESP) pela concessão de bolsa de Iniciação Científica ao segundo autor.

\section{REFERÊNCIAS}

ALTUNA B et al. 2000. Obtencion de Acido Jasmonico a partir de $B$. theobromae por cultivo submergido. Effecto em la agricultura. Anales Cientificos de la XX RELAR, p. 269.

CARLETI R; MORAES DM; VILLELA FA. 1999. Jasmonato: Influência na germinação de sementes de alface (Lactuca sativa L.). Revista Brasileira de Sementes 21: 183-186.

CARLI AP. 1999. Efeito do ácido jasmônico na síntese de lipoxigenase e de inibidores de proteases em sementes de explantes de soja. Viçosa: UFV. 52p. (Tese mestrado).

CASTRO G; KRAUS T; ABDALA G. 1999. Endogenous jasmonic acid and radial cell expansion in buds of potato tubers. Journal of Plant Physiology 155: 706-710.

CORTÊS HP. 2000. Introdução aos hormônios Vegetais; EMBRAPA, p.131-157.

CREELMAN RA; MULLET JE. 1997. Biosynthesis and action of jasmonate in plants. Annual Review of Plant and Molecular Biology 48: 355-381.

DHANDHUKIA PC; THAKKAR VR. 2008. Response surface methodology to optimize the nutritional parameters for enhanced production of jasmonic acid by Lasiodiplodia theobromae. Journal of Applied Microbiology 105: 636-643.

ENG F; GUTIÉRREZ-ROJAS M; FAVELATORRES E. 1998. Culture conditions for jasmonic acid and biomass production by Botryodiplodia theobromae in submerged fermentation. Process Biochemistry 33: 715-720.

FARMER EE; RYAN CA. 1990. Interplant communication: airborn methyl jasmonate induces synthesis of proteinase inhibitors in plant leaves. Proceedings National Academy of Sciences 87: 7713-7716.

FONSECA RM. 2006. Caracterização morfológica de genótipos de Capsicum chinense Jacq do alto do Rio Negro-AM. Manaus: UFAM. 51p. (Tese mestrado).

HAMBERG M; GARDER HW. 1992 Oxylipin pathway to jasmonates: biochemistry and biological significance. Biochimica et Biophysica Acta 1165: 1-18.

KODA Y. 1992. The role of jasmonic acid and related compounds in the regulation of plant development. International. Review of Cytology 135: 155-159.

LÉON J; SÁNCHES-SERRANO JJ. 1999. Molecular bioloy of jasmonic acid biosynthesis in plants. Plant Physiology and Biochemistry 37: 373-380.

MEYER A et al. 1984. Ocurrence of the plant growth regulators jasmonic acid in plants. Journal of Plant Growth Regulator 3: 1-8.

MENDES MSA et al. 1998. Fungos em plantas no Brasil. EMBRAPA, p. 280-321.

MIERSCH O et al. 1987. (+)-Isojasmonic acid and related compounds from Botryodiplodia theobromae. Phytochemistry 26: 1037-1039.

MIERSCH O; SCHMIDT J; SEMBDNER G; SCHREIBER K. 1989. Jasmonic-acid like substances from culture filtrate of Botryodiplodia theobromae. Phytochemistry 28: 1303-1305.

PARTHIER B. 1991. Jasmonate hormonal regulators or stress factors in leaf senescence? Journal of Plant and Growth Regulator 9: 1-7.

RIBEIRO JM et al. 2002. Physalis angulata L. antineoplasic activity, in vitro, evaluation from it's ítems and fruit capsules. Revista Brasileira de Farmacognosia, 12 supl: 21-23.

SCHALLER F. 2001. Enzymes of the biosynthesis of octadecanoid derived signaling molecules. Journal of Experimental Botany 52: 11-23.

SEMBDNER G; PARTHIER B. 1993. The biochemistry and the physiological and molecular actions the jasmonates. Annual Review of Plant Physiology Plant Molecular Biology 44: 569-589.

TEBAYASHI A; HORIBATA Y; MIKAGI E; KASHIWAGI T; MEKURIA DB; DEKEBO A; ISHIHARA A; KIM C. 2007. Induction of resistance against the Leafminer, Liriomyza trifolii, by jasmonic acid in sweet pepper. Biosc. Biotechnol. Biochem 71:1521-1526. 